\title{
The Sustainability of Thailand's Protected-Area System under Climate Change
}

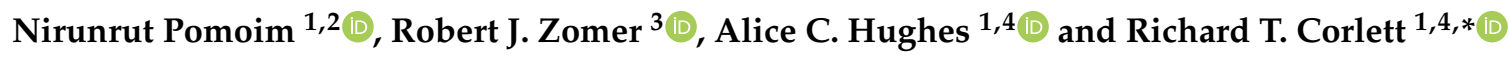 \\ 1 Center for Integrative Conservation, Xishuangbanna Tropical Botanical Garden, Chinese Academy of \\ Sciences, Menglun 666303, China; nirunrut@xtbg.ac.cn (N.P.); ach_conservation2@hotmail.com (A.C.H.) \\ 2 University of Chinese Academy of Sciences, Beijing 100049, China \\ 3 Center for Mountain Futures, Kunming Institute of Botany, Chinese Academy of Sciences, \\ Kunming 650201, China; r.zomer@mac.com \\ 4 Center of Conservation Biology, Core Botanical Gardens, Chinese Academy of Sciences, \\ Menglun 666303, China \\ * Correspondence: corlett@xtbg.org.cn; Tel.: +86-182-8805-9408
}

Citation: Pomoim, N.; Zomer, R.J.; Hughes, A.C.; Corlett, R.T. The Sustainability of Thailand's Protected-Area System under Climate Change. Sustainability 2021, 13, 2868. https://doi.org/10.3390/su13052868

Academic Editor: Jeroen Meersmans

Received: 6 February 2021

Accepted: 1 March 2021

Published: 6 March 2021

Publisher's Note: MDPI stays neutral with regard to jurisdictional claims in published maps and institutional affiliations.

Copyright: (c) 2021 by the authors. Licensee MDPI, Basel, Switzerland. This article is an open access article distributed under the terms and conditions of the Creative Commons Attribution (CC BY) license (https:// creativecommons.org/licenses/by/ $4.0 /)$.

\begin{abstract}
Protected areas are the backbone of biodiversity conservation but vulnerable to climate change. Thailand has a large and well-planned protected area system, covering most remaining natural vegetation. A statistically derived global environmental stratification (GEnS) was used to predict changes in bioclimatic conditions across the protected area system for 2050 and 2070, based on projections from three CMIP5 earth system models and two representative concentration pathways (RCPs). Five bioclimatic zones were identified composed of 28 strata. Substantial spatial reorganization of bioclimates is projected in the next 50 years, even under RCP2.6, while under RCP8.5 the average upward shift for all zones by 2070 is $328-483 \mathrm{~m}$ and the coolest zone disappears with two models. Overall, 7.9-31.0\% of Thailand's land area will change zone by 2070, and 31.7-90.2\% will change stratum. The consequences for biodiversity are less clear, particularly in the lowlands where the existing vegetation mosaic is determined largely by factors other than climate. Increasing connectivity of protected areas along temperature and rainfall gradients would allow species to migrate in response to climate change, but this will be difficult in much of Thailand. For isolated protected areas and species that cannot move fast enough, more active, species-specific interventions may be necessary.
\end{abstract}

Keywords: bioclimates; biodiversity; conservation planning; national parks; Southeast Asia; tropical Asia; tropical forests

\section{Introduction}

Protected areas are the backbone of global biodiversity conservation, as well as making a major contribution to the provision of key ecosystem services, including carbon sequestration, erosion control, the supply of clean water, and ecotourism. Protected areas are fixed in place, however, and thus vulnerable to anthropogenic climate change, which may make some or all of the protected area unsuitable for some of the species at which it is targeted [1]. Despite this vulnerability, there is evidence that protected areas can act as a buffer against some of the detrimental effects of climate change [2]. Moreover, protected areas and protected-area systems can be managed in ways that reduce these impacts [3]. A recent study suggested that expanding the proportion of the total protected land area to $30 \%$ (from c. $15 \%$ currently), coupled with limiting global warming to $2{ }^{\circ} \mathrm{C}$, would more than halve tropical extinction risks [4]. The current working version of the Convention on Biological Diversity's post-2020 framework, due to be confirmed at a meeting in China in 2021 , includes $30 \%$ as a draft target [5]. If this ambition is to be achieved, however, and is to be effective in conserving biodiversity, we need to understand how protected areas will be impacted by climate change in the coming decades and how these impacts can be reduced. 
Thailand is at the center of Southeast Asia and is bordered by Laos, Cambodia, Myanmar, and Malaysia (Figure 1). The total land area is $517,624 \mathrm{~km}^{2}$, ranging in altitude from 0 to $2564 \mathrm{~m}$ above mean sea level. The climate is tropical, with distinct wet and dry seasons associated with the Asian summer and winter monsoons, respectively. Biogeographically, most of the country is part of the Indochinese subregion, with the southern part of the peninsula in Sundaland [6]. Forests of various types cover at least $31 \%$ of the country's total area [7]. Thailand is entirely within the Indo-Burma biodiversity hotspot, and it has been estimated that it supports $10 \%$ of the world's described vertebrate species and at least $5 \%$ of described vascular plants [8,9]. Until the 1990s, deforestation and forest degradation made a significant contribution to Thailand's greenhouse gas emissions, but they have decreased substantially since then, and these emissions are now more than offset by uptake from plantations [10]. Despite this, protecting and rehabilitating forests is still an important component of Thailand's overall climate change mitigation and adaptation strategy, as set out in its Third National Communication to the UNFCCC [10].

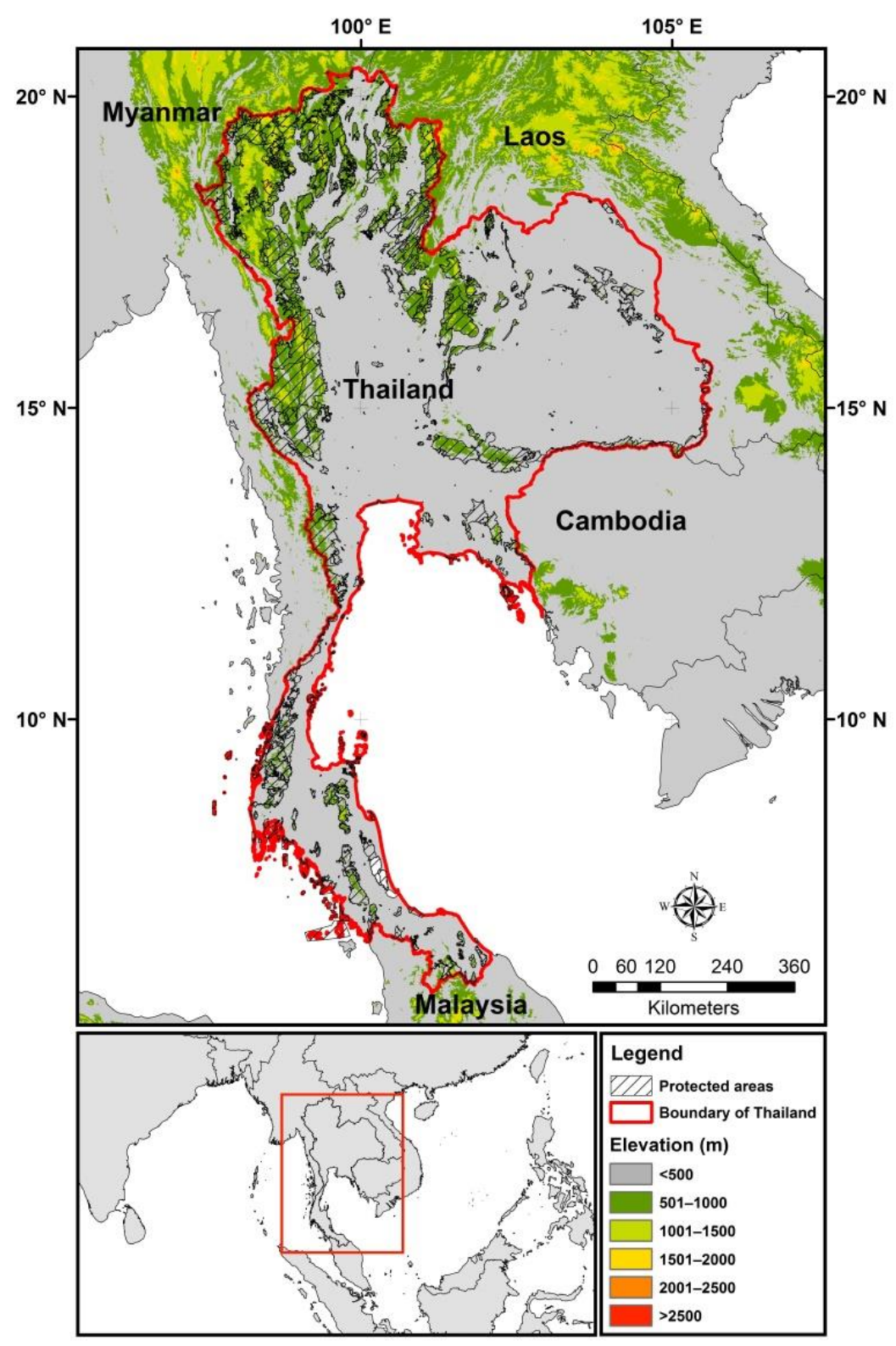

Figure 1. The current protected-area system in Thailand. 
Thailand's protected-area system (Figure 1) was started in 1962. The gazetted protected areas in 2020 consist of 132 National Parks, 60 Wildlife Sanctuaries, and 80 Nonhunting Areas, as well as 114 Forest Parks, 13 Botanical Gardens, and 55 Arboreta. Currently, the Department of National Parks, Wildlife, and Plant Conservation (DNP) is in the process of establishing at least 23 additional National Parks and 7 Non-hunting Areas. In total, these protected areas cover approximately $118,320 \mathrm{~km}^{2}$ or $22.8 \%$ of the country's land area [11], making Thailand one of the relatively few tropical countries that has achieved the CBD's 2020 area target (Aichi target 11) of 17\%. The Thai government aims to increase this to at least $25 \%$ of the country by 2025 . The existing protected areas are distributed among the regions, but they are mainly in the north and the west of the country, with few in the densely populated center and east. Despite the large total area, some lowland ecosystems are not adequately represented at present (i.e., peat swamp forest, mangrove forest, and lowland deciduous forest), and Thailand's protected areas are relatively fragmented. Only $8 \%$ are $>1000 \mathrm{~km}^{2}$ and are considered to have the potential to maintain large mammal populations, especially tigers, leopards, and elephants [12]. About 54\% are $100-500 \mathrm{~km}^{2}$, and $38 \%$ are $<100 \mathrm{~km}^{2}$.

Ideally, conservation planning would be based on a comprehensive knowledge of the distribution of wild species in the area of concern. Thailand has relatively good biodiversity data by tropical standards, but knowledge of hyperdiverse tropical systems is always incomplete; therefore, that planning must be based on a few relatively wellstudied taxa: typically, birds, medium and large mammals, and trees [13]. In this paper, we therefore use a statistically derived bioclimatic stratification [14] as a proxy for biodiversity distributions, including the distributions of the numerous species for which little or no data exist. Climate per se is not a direct target for conservation, and not the only determinant of distributions, but this allows for a uniform approach that can be applied to the whole country. Moreover, the Royal Forest Department of Thailand has recently mapped the vegetation of the country at 1:50,000, using Sentinel-2 and Landsat 8 images from 2018 and extensive ground checking [8]. It is thus possible to compare the physical map of climate types with an independently derived vegetation map to assess the importance of climate as a driver of vegetation patterns and also to identify potential threats from climate change to habitat availability.

The main objectives of this study were therefore as follows:

1. To assess the spatial patterns of climate change projected for Thailand by 2050 and 2070.

2. To produce a bioclimatic stratification for the present climate of Thailand and the projected climates for 2050 and 2070.

3. To assess the ability of the existing protected-area system to represent the climate types currently present in Thailand.

4. To assess the impacts of the projected climate change by 2050 and 2070 on the representation of climate types within the protected-area system and in individual protected areas.

5. To assess the usefulness of climate as a proxy for biodiversity and identify the potential impacts of climate change on the protection of biodiversity in a protected-area system.

\section{Materials and Methods}

We used a geospatial modeling approach based upon the global environmental stratification (GEnS [14]) to analyze the projected distribution of bioclimatic conditions within Thailand by the years 2050 and 2070. A similar approach has previously been used in Yunnan, China [15], in the transboundary Kailash Sacred Landscape of China, India, and Nepal [16], as well as in Myanmar [17]. We used GEnS v. 1 [14], which characterizes recent conditions based on high-resolution geospatial monthly climate datasets averaged from 1960 to 2000 [18]. The GEnS classifies the world's land surface into 125 relatively homogeneous bioclimatic strata, aggregated into 18 zones: the zones have descriptive names (written with uppercase initial letters to avoid confusion with other descriptions), 
and the strata each have unique alphanumeric codes. We used a multivariate analysis (the maximum likelihood classification algorithm in ArcMap 10.5 to cluster the statistical signature profiles of the original GEnS strata to be the bioclimatic stratification for Thailand, based upon the WorldClim V.1.4 dataset, which is the current climate condition. We reconstructed from raster format to perform spatial analyses with a GIS. We used the Delta method [19] to downscale to $1000 \mathrm{~m}^{2}$ resolution [15,20], because this is intermediate in scale between the fine resolution of the topographic maps and the coarse resolution of the climatic variables and corresponds to the minimum mapping unit of the vegetation-type map used in this study.

The method used to develop the stratification of current conditions was also used for predicted future climate conditions. Climate projections for the years 2050 (averaged over 2041-2060) and 2070 (average over 2061-2080), also obtained from WorldClim, were chosen to represent a short- to medium-term time frame relevant to the needs of ecosystem managers, planners, and other policy and decision makers. We developed the stratification based upon predicted future climate conditions using three earth system models (HadGEM2-ES, CNRM-CM5, and GFDL-CM3), previously used in Southeast Asia, to create climate predictions under two representative concentration pathways, RCP2.6 and RCP8.5, representing low and high greenhouse-gas concentration scenarios, respectively [21]. RCP2.6 is consistent with the Paris Agreement's $2{ }^{\circ} \mathrm{C}$ global warming target.

\section{Results}

\subsection{Projected Climate Change for the Whole of Thailand}

The baseline mean annual temperature for Thailand (1960-2000) was $26.1^{\circ} \mathrm{C}$, mean maximum temperature of the warmest month was $34.9^{\circ} \mathrm{C}$, and mean annual precipitation was $1498 \mathrm{~mm}$ (Table 1). All projections for the future show a continuation of recent warming trends (Table 1; Figures S1-S4). By 2050, the projected increase in mean annual temperature is $1.1-1.9^{\circ} \mathrm{C}$ under RCP2.6 and $1.7-3.1^{\circ} \mathrm{C}$ under RCP8.5. The increase is greatest in the northern parts of Thailand, approaching and exceeding $3.0^{\circ} \mathrm{C}$ under RCP8.5 with GFDLCM3 and HadGEM2-ES. By 2070, the projected increase is $1.2-2.1^{\circ} \mathrm{C}$ under RCP2.6 and 2.6-4.5 ${ }^{\circ} \mathrm{C}$ under RCP8.5, approaching and exceeding $4.0^{\circ} \mathrm{C}$ under RCP8.5 with GFDL-CM3 and HadGEM2-ES. Projected increases in maximum temperature of the warmest month are similar: $0.9-1.8^{\circ} \mathrm{C}$ under RCP2.6 and $1.4-3.0^{\circ} \mathrm{C}$ under RCP8.5 by 2050, and $0.7-2.1{ }^{\circ} \mathrm{C}$ under RCP2.6 and $2.6-4.4^{\circ} \mathrm{C}$ under RCP8.5 by 2070. Projected mean annual precipitation (Table 1; Figures S5 and S6) shows a wider spread between the models. CNRM-CM5 and GFDL-CM3 project increases of 3.5-4.8\% under RCP2.6 and 1.3-6.4\% under RCP8.5 by 2050 and increases of $3.1-7.2 \%$ under RCP2.6 and $6.4-7.7 \%$ under RCP 8.5 by 2070 . By contrast, HadGEM2-ES projects decreases of $1.8 \%$ under RCP2.6 and $8.8 \%$ under RCP8.5 by 2050 and $2.6 \%$ under RCP2.6 and $8.4 \%$ under RCP 8.5 by 2070 . Note, however, that all these projected changes in precipitation are small compared with both current interannual variation and longer-term tree-ring oxygen isotope records [22]. 
Table 1. Mean annual temperature, maximum temperature of the warmest month, and precipitation averaged for the years 1960-2000 and projected for 2050 and 2070 with three ESMs under two representative concentration pathways (RCPs).

\begin{tabular}{|c|c|c|c|c|c|c|c|c|c|c|}
\hline \multirow[t]{2}{*}{ Year/RCP } & \multirow[t]{2}{*}{ Model } & \multicolumn{3}{|c|}{$\begin{array}{c}\text { Mean Annual } \\
\text { Temperature }\left({ }^{\circ} \mathrm{C}\right)\end{array}$} & \multicolumn{3}{|c|}{$\begin{array}{c}\text { Maximum } \\
\text { Temperature }\left({ }^{\circ} \mathrm{C}\right)\end{array}$} & \multicolumn{3}{|c|}{$\begin{array}{c}\text { Mean Annual } \\
\text { Precipitation }(\mathrm{mm})\end{array}$} \\
\hline & & Mean & Min & $\operatorname{Max}$ & Mean & Min & $\operatorname{Max}$ & Mean & Min & $\operatorname{Max}$ \\
\hline $\begin{array}{l}1960-2000 \\
2050\end{array}$ & & 26.1 & 14.8 & 28.9 & 34.9 & 24.3 & 39.2 & 1498 & 856 & 4458 \\
\hline \multirow[t]{3}{*}{$\mathrm{RCP} 2.6$} & CNRM-CM5 & 27.2 & 15.9 & 29.9 & 35.8 & 25.1 & 40.2 & 1570 & 917 & 4546 \\
\hline & GFDL-CM3 & 28.0 & 16.7 & 30.6 & 36.6 & 26.1 & 40.9 & 1550 & 846 & 4512 \\
\hline & HadGEM2-ES & 28.0 & 16.8 & 30.5 & 36.7 & 26.0 & 41.0 & 1471 & 868 & 4412 \\
\hline \multirow[t]{3}{*}{ RCP8.5 } & CNRM-CM5 & 27.8 & 16.5 & 30.5 & 36.3 & 25.7 & 40.4 & 1594 & 907 & 4699 \\
\hline & GFDL-CM3 & 28.8 & 17.6 & 31.4 & 37.7 & 26.9 & 42.2 & 1518 & 780 & 4615 \\
\hline & HadGEM2-ES & 29.2 & 18.0 & 31.4 & 37.9 & 27.2 & 41.9 & 1367 & 790 & 4069 \\
\hline \multicolumn{11}{|l|}{2070} \\
\hline \multirow[t]{3}{*}{ RCP2.6 } & CNRM-CM5 & 27.3 & 16.0 & 30.0 & 35.6 & 25.0 & 39.7 & 1545 & 824 & 4487 \\
\hline & GFDL-CM3 & 28.2 & 17.0 & 30.8 & 36.9 & 26.1 & 41.2 & 1606 & 892 & 4547 \\
\hline & HadGEM2-ES & 28.1 & 16.8 & 30.5 & 37.0 & 26.2 & 41.0 & 1459 & 874 & 4371 \\
\hline \multirow[t]{3}{*}{ RCP8.5 } & CNRM-CM5 & 28.7 & 17.4 & 31.2 & 37.5 & 26.6 & 41.8 & 1594 & 868 & 4720 \\
\hline & GFDL-CM3 & 30.0 & 18.7 & 32.7 & 38.3 & 27.8 & 42.6 & 1614 & 846 & 4600 \\
\hline & HadGEM2-ES & 30.6 & 19.4 & 32.9 & 39.3 & 28.3 & 43.2 & 1372 & 844 & 4091 \\
\hline
\end{tabular}

\subsection{Bioclimate Stratification of Thailand under Current Conditions}

The environmental stratification of Thailand identified five bioclimatic zones composed of 28 strata (Figure 2; Table 2; Table S1). The lowlands include two zones: Extremely Hot and Moist, composed of 10 strata and comprising 51\% of the total land area, and Extremely Hot and Xeric, with three strata and comprising 39\%. These two zones are distinguished by rainfall. Above the lowlands are decreasing areas of Hot and Mesic (seven strata, $8.5 \%$ ), Hot and Dry (five strata, $1.1 \%$ ), and, on the highest peaks, Warm Temperate and Mesic (three strata, $<0.1 \%$ ) zones. Mean annual temperatures of zones and strata decline consistently with their mean elevations, but there is no simple trend in precipitation.

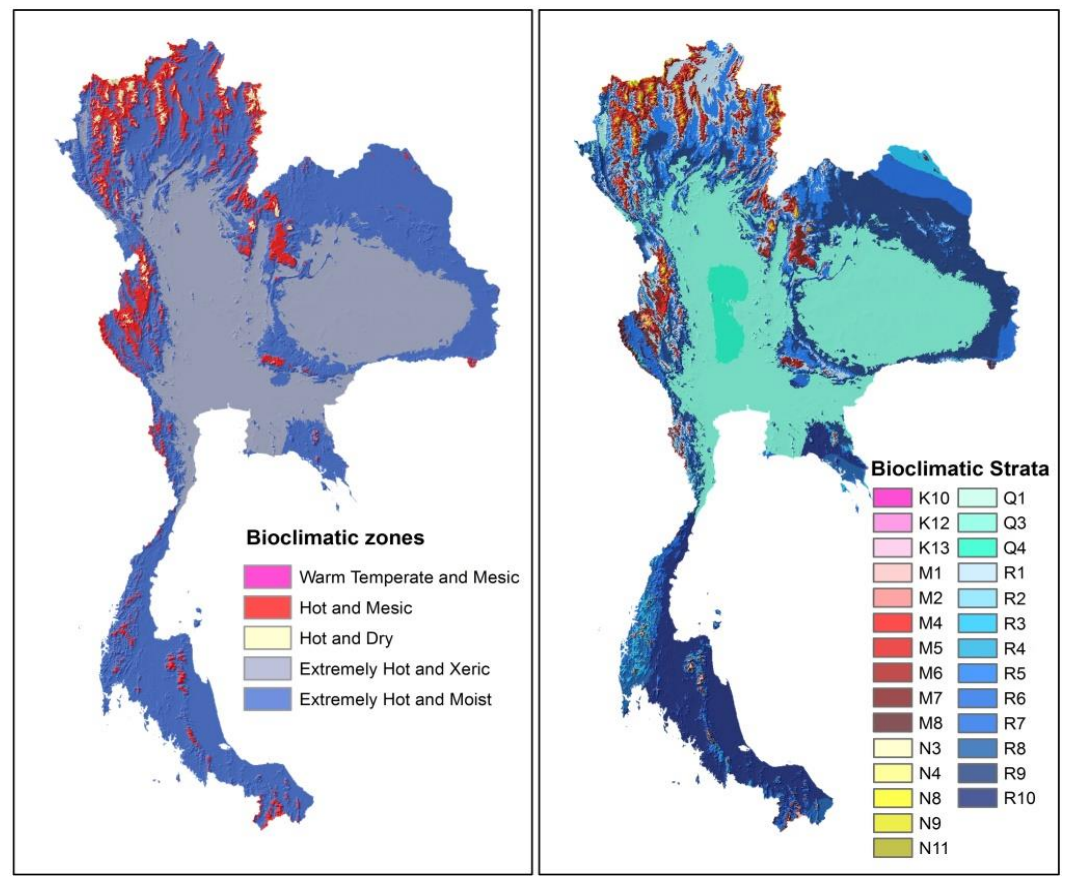

Figure 2. Distribution of the bioclimatic zones and strata in Thailand based on weather station data from 1960-2000. 
Table 2. Characteristics of the bioclimatic zones based on climate data from 1960 to 2000, showing the area, mean elevation, mean annual temperature, maximum temperature of the warmest month, and mean annual precipitation.

\begin{tabular}{lrrrrr}
\hline \multicolumn{1}{c}{ Bioclimatic Zone } & $\begin{array}{c}\text { Area } \\
\left(\mathbf{k m}^{\mathbf{2}}\right)\end{array}$ & $\begin{array}{c}\text { Mean } \\
\text { Elevation (m) }\end{array}$ & $\begin{array}{c}\text { Mean Annual } \\
\text { Temperature }\left({ }^{\circ} \mathbf{C}\right)\end{array}$ & $\begin{array}{c}\text { Maximum } \\
\text { Temperature }\left({ }^{\circ} \mathbf{C}\right)\end{array}$ & $\begin{array}{c}\text { Mean Annual } \\
\text { Precipitation }(\mathbf{m m})\end{array}$ \\
\hline Warm Temperate and Mesic & 83 & 1964 & 16.9 & 26.9 & 1325 \\
Hot and Dry & 5818 & 1343 & 20.6 & 30.8 & 1232 \\
Hot and Mesic & 43,791 & 868 & 23.0 & 32.7 & 1417 \\
Extremely Hot and Moist & 262,852 & 291 & 25.9 & 34.5 & 1686 \\
Extremely Hot and Xeric & 200,660 & 119 & 27.3 & 36.1 & 1275 \\
\hline
\end{tabular}

\subsection{Projected Changes in Bioclimates by 2050 and 2070}

By 2050, substantial changes are projected in both the areal extent and the average elevation of the bioclimatic zones by all models and in both RCP scenarios (Figure S7; Table 3). Under RCP2.6, there is a large expansion in the extent of the Extremely Hot and Xeric zone (from 200,660 to 262,570-268,007 km²), which becomes the largest zone, while the areal extents of other bioclimatic zones decrease, particularly the three cooler zones. The overall average upward shift for all zones is $145-247 \mathrm{~m}$. Under RCP8.5, by contrast, the Extremely Hot and Moist zone remains the largest using GFDL-CM3 and HadGEM2-ES, where it expands by $60,535-81,080 \mathrm{~km}^{2}$, while the other zones all decrease, and the Warm Temperate and Mesic zone disappears from Thailand. However, the CNRM-CM5 model projects a large expansion in the extent of the Extremely Hot and Xeric (from 200,660 km² to $243,051 \mathrm{~km}^{2}$ ), as under RCP2.6, and the Warm Temperate and Mesic declines greatly but does not disappear. The overall average upward shift for all zones under RCP8.5 is 206-326 m. Changes in the more narrowly defined strata are larger than in the zones, with the biggest expansions in Q4 and R7, respectively the warmest, lowest-elevation strata in the Extremely Hot and Xeric and Extremely Hot and Moist zones (Figure S8; Table S2). Several strata are lost from Thailand, but none are gained. Overall, $12.1-13.1 \%$ of the total area of Thailand changes zone under RCP2.6 by 2050 and $8.3-15.8 \%$ under RCP8.5, while 31.7-60.7\% under RCP2.6 and 52.6-82.4\% under RCP8.5 change stratum (Table S3).

Projected changes by 2070 are generally in the same direction as for 2050, but larger (Figure S9; Table 4). Under RCP2.6, there is a large expansion in the extent of the Extremely Hot and Xeric zone and decreases in the other zones, except for the Extremely Hot and Moist zone with GFDL-CM3, which shows a slight increase. The overall average upward shift for all zones is 151-278 m. Under RCP8.5, in contrast, the Extremely Hot and Moist zone expands with all models, while the Extremely Hot and Xeric zone declines. All other zones also decline, with the Warm Temperate and Mesic zone disappearing with GFDLCM3 and HadGEM2-ES and reduced to only $2 \mathrm{~km}^{2}$ with CNRM-CM5. The overall average upward shift for all zones is $328-483 \mathrm{~m}$. Changes in bioclimatic strata are also similar but larger than those by 2050 and, again, several strata are lost, but none gained (Figure S10; Table S4). Overall, 7.9-13.9\% of the total area of Thailand changes zone under RCP2.6 by 2070 and $11.1-31.0 \%$ under RCP8.5, while $31.7-63.6 \%$ under RCP2.6 and $71.4-90.2 \%$ under RCP8.5 changes stratum (Table S3). 
Table 3. Projected change in areal extents and mean elevations of bioclimatic zones and their upward shifts by 2050 with three ESMs under two RCPs.

\begin{tabular}{|c|c|c|c|c|c|c|c|c|}
\hline \multirow{3}{*}{ Bioclimatic Zone } & \multirow{3}{*}{ Model } & \multicolumn{3}{|c|}{$\begin{array}{c}\text { Area } \\
\left(\mathrm{km}^{2}\right)\end{array}$} & \multicolumn{2}{|c|}{$\begin{array}{c}\text { Area Change } \\
\left(\mathrm{km}^{2}\right)\end{array}$} & \multicolumn{2}{|c|}{$\begin{array}{l}\text { Elevation Shift } \\
(\mathrm{m})\end{array}$} \\
\hline & & \multirow{2}{*}{ Current } & $\mathbf{R C P}$ & RCP & $\mathbf{R C P}$ & RCP & RCP & RCP \\
\hline & & & 2.6 & 8.5 & 2.6 & 8.5 & 2.6 & 8.5 \\
\hline \multirow{3}{*}{ Warm Temperate and Mesic } & CNRM-CM5 & \multirow{3}{*}{83} & 25 & 12 & -58 & -71 & 233 & 315 \\
\hline & GFDL-CM3 & & 4 & 0 & -79 & -83 & 410 & - \\
\hline & HadGEM2-ES & & 8 & 0 & -75 & -83 & 281 & - \\
\hline \multirow{3}{*}{ Hot and Dry } & CNRM-CM5 & \multirow{3}{*}{5818} & 1702 & 766 & -4116 & -5052 & 179 & 278 \\
\hline & GFDL-CM3 & & 426 & 127 & -5392 & -5691 & 370 & 555 \\
\hline & HadGEM2-ES & & 714 & 142 & -5104 & -5676 & 277 & 532 \\
\hline \multirow{3}{*}{ Hot and Mesic } & CNRM-CM5 & \multirow{3}{*}{43,791} & 18,140 & 10,690 & $-25,651$ & $-33,101$ & 207 & 319 \\
\hline & GFDL-CM3 & & 9005 & 3049 & $-34,786$ & $-40,742$ & 329 & 525 \\
\hline & HadGEM2-ES & & 9350 & 2956 & $-34,441$ & $-40,835$ & 327 & 512 \\
\hline \multirow{3}{*}{ Extremely Hot and Moist } & CNRM-CM5 & \multirow{3}{*}{262,852} & 227,737 & 258,686 & $-35,115$ & -4166 & 42 & 1 \\
\hline & GFDL-CM3 & & 240,582 & 343,932 & $-22,270$ & 81,080 & -12 & -87 \\
\hline & HadGEM2-ES & & 234,509 & 323,387 & $-28,343$ & 60,535 & -5 & -90 \\
\hline \multirow{3}{*}{ Extremely Hot and Xeric } & CNRM-CM5 & \multirow{3}{*}{200,660} & 265,601 & 243,051 & 64,941 & 42,391 & 63 & 115 \\
\hline & GFDL-CM3 & & 262,570 & 165,479 & 61,910 & $-35,181$ & 138 & 313 \\
\hline & HadGEM2-ES & & 268,007 & 186,103 & 67,347 & $-14,557$ & 129 & 293 \\
\hline \multirow{3}{*}{\multicolumn{2}{|c|}{ Average upward shift for all zones }} & & & & \multicolumn{2}{|c|}{ CNRM-CM5 } & 145 & 206 \\
\hline & & & & & \multicolumn{2}{|c|}{ GFDL-CM3 } & 247 & 326 \\
\hline & & & & & \multicolumn{2}{|c|}{ HadGEM2-ES } & 202 & 312 \\
\hline
\end{tabular}

Table 4. Projected change in areal extents and mean elevations of bioclimatic zones and their upward shifts by 2070 with three ESMs under two RCPs.

\begin{tabular}{|c|c|c|c|c|c|c|c|c|}
\hline \multirow{2}{*}{ Bioclimatic Zone } & \multirow{2}{*}{ Model } & \multicolumn{3}{|c|}{$\begin{array}{l}\text { Area } \\
\left(\mathbf{k m}^{2}\right)\end{array}$} & \multicolumn{2}{|c|}{$\begin{array}{l}\text { Area Change } \\
\left(\mathrm{km}^{2}\right)\end{array}$} & \multicolumn{2}{|c|}{$\begin{array}{l}\text { Elevation Shift } \\
\text { (m) }\end{array}$} \\
\hline & & Current & $\begin{array}{c}\text { RCP } \\
2.6\end{array}$ & $\begin{array}{c}\text { RCP } \\
8.5\end{array}$ & $\begin{array}{c}\text { RCP } \\
2.6\end{array}$ & $\begin{array}{c}\text { RCP } \\
8.5\end{array}$ & $\begin{array}{c}\mathrm{RCP} \\
2.6\end{array}$ & $\begin{array}{c}\text { RCP } \\
8.5\end{array}$ \\
\hline \multirow{3}{*}{ Warm Temperate and Mesic } & CNRM-CM5 & \multirow{3}{*}{83} & 20 & 2 & -63 & -81 & 240 & 521 \\
\hline & GFDL-CM3 & & 3 & 0 & -80 & -83 & 503 & - \\
\hline & HadGEM2-ES & & 8 & 0 & -75 & -83 & 281 & - \\
\hline \multirow{3}{*}{ Hot and Dry } & CNRM-CM5 & \multirow{3}{*}{5818} & 1554 & 204 & -4264 & -5614 & 189 & 480 \\
\hline & GFDL-CM3 & & 299 & 33 & -5519 & -5785 & 421 & 821 \\
\hline & HadGEM2-ES & & 676 & 35 & -5142 & -5783 & 289 & 780 \\
\hline \multirow{3}{*}{ Hot and Mesic } & CNRM-CM5 & \multirow{3}{*}{43,791} & 16,917 & 4604 & $-26,874$ & $-39,187$ & 212 & 468 \\
\hline & GFDL-CM3 & & 8035 & 857 & $-35,756$ & $-42,934$ & 335 & 643 \\
\hline & HadGEM2-ES & & 9153 & 536 & $-34,638$ & $-43,255$ & 333 & 678 \\
\hline \multirow{3}{*}{ Extremely Hot and Moist } & CNRM-CM5 & \multirow{3}{*}{262,852} & 222,317 & 320,005 & $-40,535$ & 57,153 & 44 & -62 \\
\hline & GFDL-CM3 & & 265,276 & 418,370 & 2424 & 155,518 & -35 & -93 \\
\hline & HadGEM2-ES & & 231,781 & 422,099 & $-31,071$ & 159,247 & -8 & -93 \\
\hline \multirow{3}{*}{ Extremely Hot and Xeric } & CNRM-CM5 & \multirow{3}{*}{200,660} & 271,780 & 187,773 & 71,120 & $-12,887$ & 68 & 234 \\
\hline & GFDL-CM3 & & 238,974 & 93,327 & 38,314 & 107,333 & 166 & 543 \\
\hline & HadGEM2-ES & & 270,970 & 89,918 & 70,310 & 110,742 & 133 & 566 \\
\hline \multirow{3}{*}{\multicolumn{2}{|c|}{ Average upward shift for all zones }} & & & & \multicolumn{2}{|c|}{ CNRM-CM5 } & 151 & 328 \\
\hline & & & & & \multicolumn{2}{|c|}{ GFDL-CM3 } & 278 & 479 \\
\hline & & & & & \multicolumn{2}{|c|}{ HadGEM2-ES } & 205 & 483 \\
\hline
\end{tabular}




\subsection{Bioclimatic Conditions and Changes in the Protected Areas}

Thailand's protected areas provide a fairly good representation of the bioclimatic zones present in Thailand, except that the densely populated Extremely Hot and Xeric zone is greatly underrepresented ( $4 \%$ of the total area of this zone and 39\% of the remaining natural vegetation) (Table 5). The three coolest zones are overrepresented in terms of percentage coverage (68-90\% of total area and $81-95 \%$ of remaining natural vegetation) but not in terms of absolute area. In total, $63 \%$ of the area protected is in the Extremely Hot and Moist zone, $27 \%$ in the Hot and Mesic, $6 \%$ in the Extremely Hot and Xeric, $4 \%$ in the Hot and Dry, and $<0.1 \%$ in the Warm Temperate and Mesic (Table 5). Representation of strata varies greatly but all 28 are found in at least one protected area (Table S5).

Table 5. Current representation of bioclimatic zones within protected areas in Thailand.

\begin{tabular}{lrrrrr}
\hline \multicolumn{1}{c}{ Bioclimatic Zone } & $\begin{array}{c}\text { Total Area } \\
\left(\mathbf{k m}^{\mathbf{2}}\right)\end{array}$ & $\begin{array}{c}\text { Area Protected } \\
\left(\mathbf{k m}^{\mathbf{2}} \mathbf{)}\right.\end{array}$ & $\begin{array}{c}\text { \% of Zone } \\
\text { Protected }\end{array}$ & $\begin{array}{c}\text { \% of Total } \\
\text { Area Protected }\end{array}$ & $\begin{array}{c}\text { \% Natural Vegetation } \\
\text { Protected }\end{array}$ \\
\hline Warm Temperate and Mesic & 83 & 75 & 90 & 0 & 95 \\
Hot and Dry & 5818 & 4256 & 73 & 4 & 82 \\
Hot and Mesic & 43,791 & 29,739 & 68 & 27 & 81 \\
Extremely Hot and Moist & 262,852 & 70,052 & 27 & 63 & 72 \\
Extremely Hot and Xeric & 200,660 & 7079 & 4 & 6 & 39 \\
\hline
\end{tabular}

Projected changes in climate within protected areas are similar to those for Thailand as a whole (Figure S11; Table S6). By 2050, under RCP2.6, areal representation of the Extremely Hot and Moist zone in protected areas decreases by 10.4-11.3\% with GFDL-CM3 and HadGEM-ES but increases by 3.3\% with CNRM-CM5, while with all three models, there is a large expansion in the extent of the Extremely Hot and Xeric zone in protected areas from 7079 to $24,871-42,348 \mathrm{~km}^{2}$. All other zones decrease considerably, with the Warm Temperate and Mesic zone decreasing by $66.7-94.7 \%$ (from 75 to $4-25 \mathrm{~km}^{2}$ ). Impacts are greater under RCP8.5, with the Extremely Hot and Xeric zone increasing more than four-fold to $33,863-56,610 \mathrm{~km}^{2}$ and all other zones declining. The Warm Temperate and Mesic zone disappears from Thai protected areas (and Thailand) with GFDL-CM3 and HadGEM2-ES. Up to six strata are also lost from the protected-area system, depending on the model and RCP (Figure S13; Table S7). Under RCP2.6, 18.1-31.7\% of all the area under protection is projected to shift to a different bioclimatic zone by 2070 and $26.5-44.5 \%$ to a new stratum, while under RCP8.5, 24.1-44.5\% shifts to a new zone and $39.9-68.4 \%$ to a new stratum (Table S3).

The trends shown for 2050 continue and increase by 2070 (Figure S13; Table S8). Under RCP2.6, the Extremely Hot and Moist zone decreases by 11.8-12.2\% with GFDL-CM3 and HadGEM-ES, while it increases by $1.5 \%$ with CNRM-CM5. The Extremely Hot and Xeric zone increases in all models, by $19,957-36,782 \mathrm{~km}^{2}$. All other zones decrease greatly, with the Warm Temperate and Mesic decreasing by 73.3-96\%. Under RCP8.5, the Extremely Hot and Xeric zone increases by $38,406-40,178 \mathrm{~km}^{2}$, while all other zones decrease in all models, and the Warm Temperate and Mesic zone is lost, or almost lost, from Thailand's protectedarea system. Up to 10 strata are also lost from the protected-area system, depending on the model and RCP (Figure S14; Table S9). Under RCP2.6, 18.9-33.1\% of all the area under protection is projected to shift to a different bioclimatic zone and $27.7-48.7 \%$ to a new stratum, while under RCP $8.5,34.5-36.1 \%$ shifts to a new zone and $56.4-84.5 \%$ to a new stratum (Table S3).

When protected areas are compared by the percentage of their total area that will shift to a different zone (Figure 3) or stratum (Figure S15) by 2050, changes in zone are greater at higher altitudes, especially in the northern, more mountainous regions, and increase under the higher-emission scenario. The percentage of the total area of each individual protected area which shifts to a different bioclimatic zone is an indicator of its exposure to climate-change impact. By 2050, 63-69\% of all protected areas are projected to show some shifts to a different bioclimatic zone under RCP2.6 and 70-75\% under RCP8.5 (Table S10). 
Moreover, $5-12 \%$ of all protected areas shift completely to different zones under RCP2.6 and $10-24 \%$ under RCP8.5. For the more narrowly defined strata, $95-100 \%$ of all protected areas are projected to show some shifts under RCP2.6 and 99-100\% under RCP8.5, and $20-39 \%$ of all protected areas shift completely to different strata under RCP2.6 and $33-55 \%$ under RCP8.5.

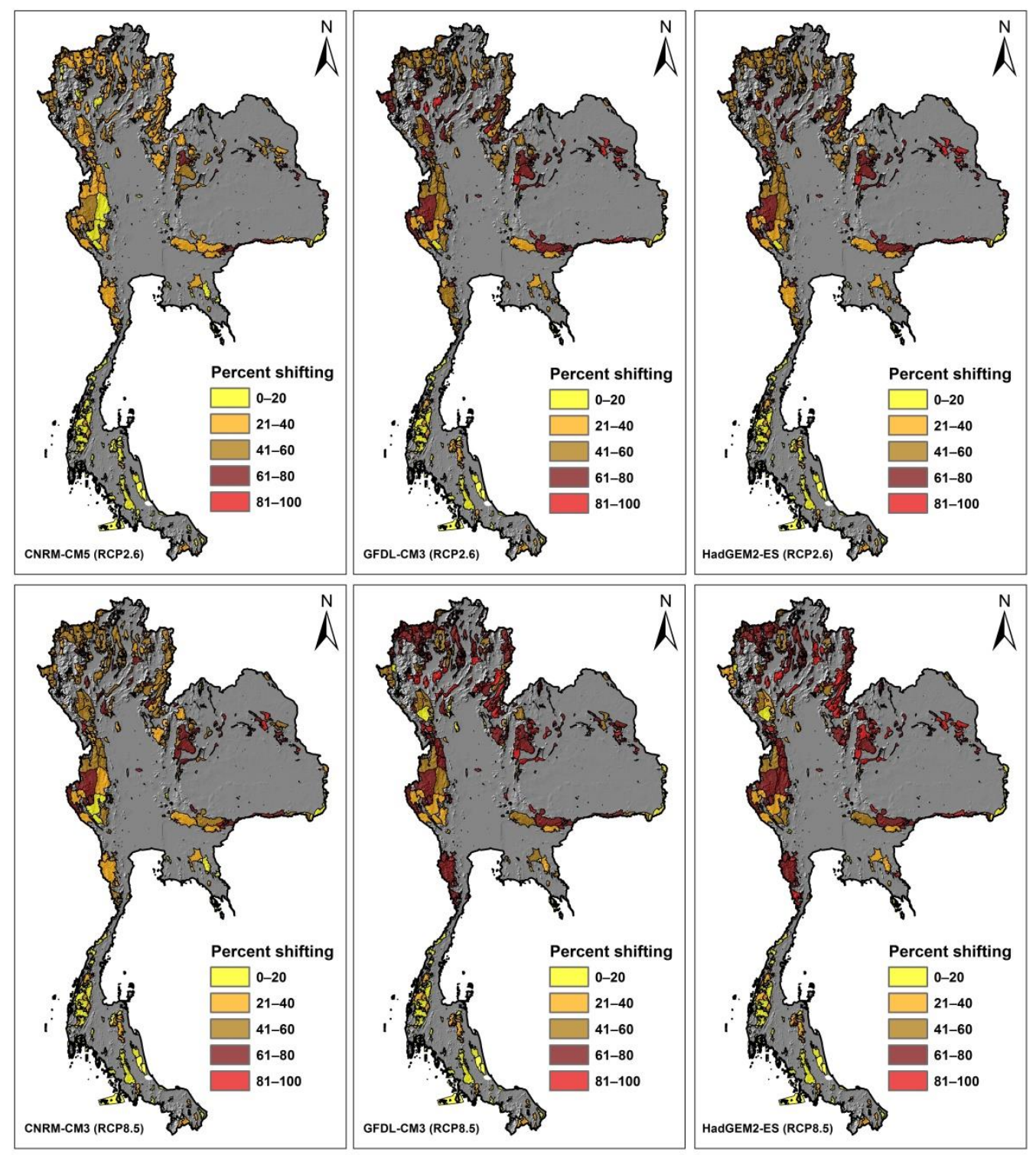

Figure 3. Percentage of each individual protected area shifting to a different bioclimatic zone by the year 2050 for three earth system models and two RCPs.

Projected changes by 2070 are similar in spatial pattern to those by 2050. By 2070, $64-70 \%$ of all protected areas are projected to show shifts to a different bioclimatic zone under RCP2.6 and $66-72 \%$ under RCP8.5, while $5-13 \%$ of all protected areas shift completely to different zones under RCP2.6 and 5-18\% under RCP8.5 (Figure 4; Table S11). For strata, $95-99 \%$ of all protected areas are projected to show some shifts under RCP2.6 and $99-100 \%$ under RCP8.5, while $20-40 \%$ under RCP2.6 and $46-68 \%$ under RCP 8.5 are projected to shift completely to different strata (Figure S16; Table S11). 

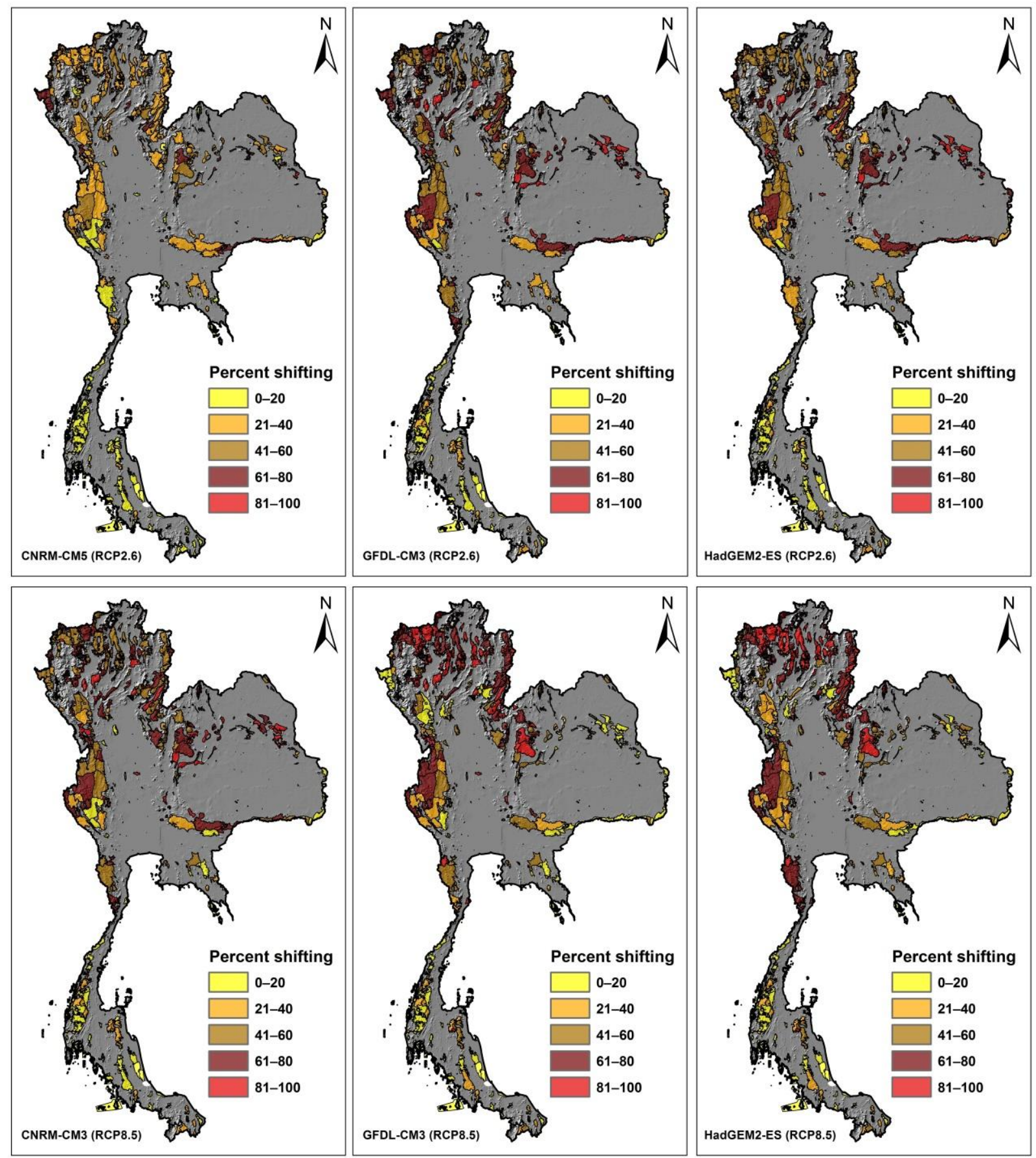

Figure 4. Percentage of each individual protected area shifting to a different bioclimatic zone by 2070 across three earth system models and two RCPs.

\subsection{Bioclimates, Bioclimatic Change, and Vegetation}

The bioclimatic stratification does not, in general, predict the current vegetation in Thailand (Table 6). This is consistent with the existence of a mosaic of distinct vegetation types in areas of apparently uniform climate, as shown in the 1:50,000 vegetation map [8] and attributed in the literature to differences in soil, water availability, fire regime, and other past and present human impacts, including shifting cultivation [23,24]. The exception is the Warm Temperate and Mesic zone, which is largely covered in hill evergreen forest. This forest type also dominates the Hot and Dry zone, the next highest elevation, and is prominent in the Hot and Mesic zone. In lowland areas, deciduous dipterocarp forest, 
mixed deciduous forest, and dry evergreen forest form a mosaic over much of Thailand, while moist evergreen forest is largely confined to the wetter Extremely Hot and Moist zone. Grasslands, assumed to be secondary, occur in all zones, while "other natural vegetation", which includes mangrove, beach forest, freshwater swamp forest, and peat forest, are entirely lowland and mostly in the Extremely Hot and Moist zone.

Table 6. The occurrence of major vegetation types within the current bioclimatic zones in Thailand.

\begin{tabular}{|c|c|c|c|c|c|c|}
\hline \multirow[b]{2}{*}{ Vegetation Type } & \multicolumn{6}{|c|}{ Area $\left(\mathbf{k m}^{2}\right)$} \\
\hline & $\begin{array}{l}\text { Warm Temperate } \\
\text { and Mesic }\end{array}$ & Hot and Dry & Hot and Mesic & $\begin{array}{c}\text { Extremely } \\
\text { Hot and } \\
\text { Moist }\end{array}$ & $\begin{array}{c}\text { Extremely } \\
\text { Hot and } \\
\text { Xeric }\end{array}$ & $\begin{array}{c}\text { Total } \\
\text { Area of Type }\end{array}$ \\
\hline Hill evergreen forest & 76 & 3836 & 10,435 & 3028 & 8 & 17,383 \\
\hline Pine forest & 0 & 262 & 587 & 39 & 0 & 888 \\
\hline Deciduous dipterocarp forest & 0 & 0 & 785 & 13,452 & 4757 & 18,994 \\
\hline Mixed deciduous forest & 2 & 618 & 14,587 & 49,941 & 10,660 & 75,808 \\
\hline Dry evergreen forest & 0 & 338 & 6300 & 13,280 & 2180 & 22,098 \\
\hline Moist evergreen forest & 0 & 13 & 3793 & 14,732 & 15 & 18,553 \\
\hline Grassland & 1 & 102 & 311 & 147 & 23 & 584 \\
\hline Other natural vegetation & 0 & 0 & 0 & 2444 & 446 & 2890 \\
\hline Total natural vegetation & 79 & 5169 & 36,798 & 97,063 & 18,089 & 157,198 \\
\hline Total area of zone & 83 & 5818 & 43,791 & 262,852 & 200,660 & \\
\hline$\%$ of zone vegetated & $95 \%$ & $89 \%$ & $84 \%$ & $37 \%$ & $9 \%$ & \\
\hline
\end{tabular}

Over the next 30-50 years, the existing vegetation within the protected areas will be impacted by the redistribution of bioclimatic zones described in the previous section. In the longer term, the vegetation types will also change, but over the next few decades climate will change more rapidly. The most dramatic changes will be in the areas currently within the three cooler zones, where expansion of the two Extremely Hot zones will impact the hill evergreen and pine forests (Figures S17 and S18). There will also be some expansion of the Extremely Hot and Xeric zone in lowland areas currently occupied by deciduous dipterocarp forest, mixed deciduous forest, and dry evergreen forest. However, these vegetation types already occur within this zone (Table 6), suggesting some degree of tolerance. The area currently occupied by moist evergreen forest, in contrast, shows relatively little change

\section{Discussion}

Thailand has a relatively large and well-planned protected-area system, covering most of the remaining natural vegetation in the country. Most of the land area is in two "Extremely Hot" lowland bioclimatic zones, with $<10 \%$ in the remaining cooler, montane areas, although these zones retain more natural vegetation than in the lowlands. Natural habitats in all five zones and 28 strata identified in the bioclimatic stratification are represented in protected areas, and, in four out of the five zones, $>70 \%$ of the remaining forest is protected. The exception is the Extremely Hot and Xeric zone, which dominates in the densely populated center and east of the country. Only $4 \%$ of this zone is protected and only $39 \%$ of its remaining forest. However, most of the currently unprotected forest in this zone-mostly deciduous dipterocarp forest and mixed deciduous forest-is highly fragmented, so opportunities for expanding protection without extensive ecological restoration are limited.

The earth system models used in this study all project an acceleration of recent warming trends across the whole of Thailand under both RCPs. In contrast, projected changes in the amount and spatial distribution of rainfall vary between models but are almost always small relative to current interannual and longer-term variability. The models predict a drastic spatial reorganization of the bioclimates by 2070 under the high-emission RCP8.5 scenario, but even under the Paris-compliant RCP2.6 low-emissions scenario the changes are still substantial. The hottest zones and strata are projected to expand, and all the cooler zones are projected to shrink, with large upward shifts for all zones by 2070. Up to $31 \%$ of Thailand's land area changes bioclimatic zone by 2070 , depending on the 
model and RCP scenario, while up to $90 \%$ changes stratum. Note, however, the significant variation between the projections from the three models and, moreover, that these models do not represent the full uncertainty in climate projections.

Projected changes within the protected-area system are similar to those in the country as a whole, but the amount of change projected for individual reserves is very varied (Tables S12-S16). The Warm Temperate and Mesic zone will disappear from the summit regions of the six National Parks which currently include it, while the areas of the montane Hot and Dry and Hot and Mesic zones will shrink substantially in these and in several other large protected areas. Many of the smallest protected areas will switch entirely to a new bioclimatic zone, potentially threatening the species and ecosystems they were established to protect. By contrast, changes in the coastal and marine protected areas are generally smaller due to thermal buffering.

Understanding the consequences of these climatic changes for biodiversity is complicated by the existence, over much of lowland Thailand, of a mosaic of three structurally and floristically distinct forest types-deciduous dipterocarp forest, mixed deciduous forest, and dry evergreen forest. This pattern is not predicted by climate variables and has been attributed to spatial patterns in soil factors, water availability, fire regimes, and other past and present human impacts, particularly the legacy of shifting cultivation $[23,24]$. The relative importance of climate versus vegetation structure and floristic composition in determining the suitability of an area as habitat differs between taxa, but it seems likely that both will be important for many species. This, in turn, makes it difficult to predict the impacts of the projected climate change on the floras and faunas of lowland areas. Moreover, these forest types were broadly defined for the purpose of mapping from space, and there is considerable floristic variation within each type. In hill evergreen forest, in particular, few species are shared between the lowest and highest altitude stands.

An additional complication comes from the rising concentrations of carbon dioxide, already almost 50\% above pre-industrial levels. This rise is not only the largest single driver of climate change but also has a direct impact on plant physiology and thus on growth, competition, and the resulting vegetation [25]. A recent study simulating the impacts of climate change on vegetation in South Asia with and without increasing $\mathrm{CO}_{2}$ found that simulations with increasing $\mathrm{CO}_{2}$ resulted in transitions from savanna into forest and deciduous forest into evergreen forest which did not occur in the absence of these increases [25]. The vegetation model used (aDGVM2) did not include nutrient limitation, meaning that the impacts of elevated $\mathrm{CO}_{2}$ may have been overestimated, but woody invasion of savannas in other parts of the world has been attributed, in part, to this mechanism [26]. Canopy closure, in turn, suppresses the grasses on which large grazing mammals depend and reduces the ability of a protected area to support such species.

Climate per se is likely to be most important at higher altitudes, where low temperatures increasingly limit survival and growth, and at the wetter end of the lowland rainfall spectrum, where drought-sensitive moist evergreen forest is important. Vegetation change will undoubtedly lag behind climate change but, at least in steep topography where dispersal distances are short, upslope dispersal of plants and animals from lower altitudes is likely to increase competition for montane taxa that are increasingly stressed by warming climates. Most of the 20 tree species studied in Natma Taung National Park in western Myanmar had a higher proportion of juveniles at the upper end of their ranges, suggesting that their populations will eventually shift upslope [27]. On isolated mountains this may result in mountain-top extinctions for the most sensitive taxa, and all plant and animal species currently found largely or only in the Warm Temperate and Mesic Zone in Thailand should be considered under threat.

The same approach, based on the global environmental stratification, was used in a recent study of Myanmar, which neighbors Thailand to the west and northwest [17]. This shows both similarities and significant differences. Myanmar has a much greater diversity of bioclimatic zones and strata: nine zones and 41 strata, compared with only five zones and 28 strata in Thailand. This largely reflects Myanmar's greater latitudinal $\left(9^{\circ} 28^{\prime}\right.$ to 
$\left.28^{\circ} 29^{\prime} \mathrm{N}\right)$ and altitudinal $(0-5881 \mathrm{~m})$ spread. All the major vegetation types in Thailand are found in Myanmar, with additional types largely in northern Myanmar at higher latitudes and altitudes than occur in Thailand. The three cooler zones, which together occupy $<10 \%$ of Thailand's land area, are much more extensive in Myanmar, yet equally vulnerable to climate change. Taxa that can disperse between isolated mountain peaks could potentially move north from Thailand into the more extensive upland forests in Myanmar in response to warming, but there are no continuous high-altitude corridors for species which cannot disperse across large gaps.

Current plans to expand Thailand's protected-area coverage from $22.8 \%$ to $25.9 \%$ will be achieved by adding $15,796 \mathrm{~km}^{2}$ of forest reserves, previously managed by the Royal Forest Department, to the protected-area system managed by the DNP. After this is completed, the opportunities for the creation of new protected areas and the expansion of existing ones in Thailand are limited, unless large-scale ecological restoration can be undertaken on degraded and agricultural lands. Although large, interconnected protected areas are rarely possible, the Department of National Parks, Wildlife, and Plant Conservation (DNP) has adopted the concept of "forest complexes", in which smaller protected areas can be linked by conservation corridors to support wide-ranging species [28,29]. For mitigation of climate-change impacts, the most important connectivity is along temperature and rainfall gradients, so that the more-mobile species can escape warming and changes in rainfall by shifting their ranges. Several of the existing forest complexes, including the 19,699 $\mathrm{km}^{2}$ Western Forest Complex on the border with Myanmar, are aligned on a north-south axis, and will provide this capacity as connectivity is increased [28]. Many species will probably not be able to track the rapid climate change projected for the next 50 years, however [30,31]; in these cases, species-specific interventions will be necessary. Potential interventions could include in situ support and "assisted migration" to other protected areas [28]. Finally, given the uncertainties in both climate-change projections and biological responses, systematic monitoring of impacts at multiple representative sites is needed in order to guide management responses.

\section{Conclusions}

Thailand's protected-area system currently provides a good level of protection for most major ecosystems. Projected climate change over the next 50 years will result in a substantial spatial reorganization of the bioclimates even under RCP2.6. Threats to biodiversity are most likely for mountain-top endemics on isolated peaks, for the biotas of small protected areas, and those with a low elevational range, as well as, in combination with rising $\mathrm{CO}_{2}$ levels, for species dependent on open habitats vulnerable to woody encroachment. Increasing connectivity along environmental gradients would help mitigate the impacts of climate change for well-dispersed species, but isolated protected areas and poorly dispersed species will probably need additional, species-specific, interventions.

Supplementary Materials: The following are available online at https:/ / www.mdpi.com/2071-105 0/13/5/2868/s1, Figure S1: Change in mean annual temperature as projected for the year 2050 for three different earth system models under RCP2.6 and RCP8.5; Figure S2: Change in mean annual temperature as projected for the year 2070 for three different earth system models under RCP2.6 and RCP8.5; Figure S3: Change in maximum temperature of the warmest month as projected for the year 2050 for three different earth system models under RCP2.6 and RCP8.5; Figure S4: Change in maximum temperature of the warmest month as projected for the year 2070 for three different earth system models under RCP2.6 and RCP8.5; Figure S5: Change in mean annual precipitation as projected for the year 2050 for three different earth system models under RCP2.6 and RCP8.5; Figure S6: Change in mean annual precipitation as projected for the year 2070 for three different earth system models under RCP2.6 and RCP8.5; Figure S7: Bioclimatic stratification of Thailand based on spatially interpolated weather station data average from 1960 to 2000, and as projected by three earth system models under two RCPs for 2050; Figure S8: Bioclimatic strata within Thailand based on spatially interpolated weather station data average from 1960 to 2000, and as projected by three earth system models under two RCPs for 2050; Figure S9: Bioclimatic stratification of Thailand based 
on spatially interpolated weather station data averages from 1960 to 2000 and as projected by three earth system models under two RCPs for 2070; Figure S10: Bioclimatic strata within Thailand based on spatially interpolated weather station data average from 1960 to 2000 and as projected by three earth system models under two RCPs for 2070; Figure S11: Bioclimatic zones within protected areas in Thailand based on spatially interpolated weather station data average from 1960 to 2000 and as projected by three earth system models under two RCPs for 2050; Figure S12: Bioclimatic strata within protected areas in Thailand based on spatially interpolated weather station data average from 1960 to 2000 and as projected by three earth system models under two RCPs for 2050; Figure S13: Bioclimatic zones of protected areas in Thailand based on spatially interpolated weather station data average from 1960 to 2000 and as projected by three earth system models under two RCPs for 2070; Figure S14: Bioclimatic strata of protected areas in Thailand based on spatially interpolated weather station data average from 1960 to 2000 and as projected by three earth system models under two RCPs for 2070; Figure S15: Percentage of each individual protected area shifting to a different bioclimatic stratum by the year 2050 for three earth system models and two RCPs; Figure S16: Percentage of each individual protected area shifting to a different bioclimatic stratum by the year 2070 for three earth system models and two RCPs; Figure S17: Percentage of each bioclimatic zone within each of the forest types found in the protected areas in Thailand as projected for the year 2050; Figure S18: Percentage of each bioclimatic zone within each of the forest types found in the protected areas in Thailand as projected for the year 2070; Table S1: Characteristics of the bioclimatic strata based on climate data from 1960 to 2000, showing the area, mean elevation, mean annual temperature, maximum temperature of the warmest month, and mean annual precipitation within Thailand; Table S2: Projected change in areal extent and mean elevation of bioclimatic strata in Thailand and their upward shifts by 2050; Table S3: Percentages of the total area of Thailand and the total protected area shifting to a different bioclimatic zone and stratum by 2050-2070; Table S4: Projected change in areal extent and mean elevation of bioclimatic strata in Thailand and their upward shifts by 2070; Table S5: Representation of bioclimatic strata within protected areas in Thailand; Table S6: Projected change in areal extent and mean elevation of bioclimatic zones in protected areas and their upward shifts by 2050; Table S7: Projected change in areal extent and mean elevation of bioclimatic strata in protected areas and their upward shifts by 2050; Table S8: Projected change in areal extent and mean elevation of bioclimatic zones in protected areas and their upward shifts by 2070; Table S9: Projected change in areal extent and mean elevation of bioclimatic strata in protected areas and their upward shifts by 2070; Table S10: Percentage of all protected areas shifting to a different zone or stratum by 2050; Table S11: Percentage of all protected areas shifting to a different zone or stratum by 2070; Table S12: Projected changes in the areal extent of bioclimatic zones in National Parks in Thailand by 2050 and 207; Table S13: Projected changes in the areal extent of bioclimatic zones in Wildlife Sanctuaries in Thailand by 2050 and 2070; Table S14: Projected changes in the areal extent of bioclimatic zones in Non-hunting Areas in Thailand by 2050 and 2070; Table S15: Projected changes in the areal extent of bioclimatic zones in Forest Parks in Thailand by 2050 and 2070; and Table S16: Projected changes in the areal extent of bioclimatic zones in proposed National Parks and Non-hunting Areas in Thailand by 2050 and 2070.

Author Contributions: Conceptualization, N.P. and R.T.C.; methodology, N.P., R.J.Z., A.C.H. and R.T.C.; formal analysis, N.P., R.J.Z., A.C.H. and R.T.C.; writing—original draft preparation, N.P. and R.T.C.; writing-review, editing, and revision, all authors; supervision, R.T.C. and A.C.H. All authors have read and agreed to the published version of the manuscript.

Funding: This research was funded by the Global Environment Facility grant GEF-5810 "Spatial Planning for Area Conservation in Response to Climate Change (SPARC)".

Institutional Review Board Statement: Not applicable.

Informed Consent Statement: Not applicable.

Data Availability Statement: All data analyzed in this study is presented in Tables in the text and Supplementary Materials, or was obtained from publicly accessible databases cited in the text, except for the protected area shapefiles, which were provided by the Department of National Parks, Wildlife and Plant Conservation, and the vegetation type shapefiles, which were provided by the Royal Forest Department, to whom requests for data should be sent.

Acknowledgments: We want to acknowledge the following: at XTBG, Thazin Nwe, for helpful advice; at Conservation International, Patrick Roehrdanz, for support data and advice; and in 
Thailand, Yongyut Trisurat (Faculty of Forestry, Kasetsart University), for suggestions and help, the Department of National Parks, Wildlife and Plant Conservation, for providing protected-area shapefiles, and the Royal Forest Department, for providing vegetation type shapefiles.

Conflicts of Interest: The authors declare no conflict of interest. The funders had no role in the design of the study; in the collection, analyses, or interpretation of data; in the writing of the manuscript, or in the decision to publish the results.

\section{References}

1. Hoffmann, S.; Irl, S.D.H.; Beierkuhnlein, C. Predicted climate shifts within terrestrial protected areas worldwide. Nat. Commun. 2019, 10, 4787. [CrossRef] [PubMed]

2. Lehikoinen, P.; Lehikoinen, A.; Santangel, A.; Jaatinen, K.; Rajasärkkä, A. Protected areas act as a buffer against detrimental effects of climate change-Evidence from large-scale, long-term abundance data. Glob. Chang. Biol. 2019, 25, 304-313. [CrossRef]

3. Maxwell, S.L.; Cazalis, V.; Dudley, N.; Hoffmann, M.; Rodrigues, A.S.; Stolton, S.; Visconti, P.; Woodley, S.; Kingston, N.; Lewis, E.; et al. Area-based conservation in the 21st century. Nature 2020, 586, 217-227. [CrossRef]

4. Hannah, L.; Roehrdanz, P.R.; Marquet, P.A.; Enquist, B.J.; Midgley, G.; Foden, W.; Lovett, J.C.; Corlett, R.T.; Corcoran, D.; Butchart, S.H.M.; et al. 30\% land conservation and climate action reduces tropical extinction risk by more than $50 \%$. Ecography 2020, 43 , 943-953. [CrossRef]

5. UNEP. Update of the Zero Draft of the Post-2020 Global Biodiversity Framework; UN Environment Programme: Montreal, QC, Canada, 2020.

6. Parnell, J. The biogeography of the Isthmus of Kra region: A review. Nordic J. Bot. 2013, 31, 001-015. [CrossRef]

7. Royal Forest Department. The Project to Provide Database of Forest Areas in 2017-2018; Final Report; Forest Land Management Office, Royal Forest Department: Bangkok, Thailand, 2018.

8. Baillie, J.E.M.; Hilton-Taylor, C.; Stuart, S.N. IUCN Red List of Threatened Species. A Global Species Assessment; IUCN: Gland, Switzerland, 2004.

9. OEPP. Biodiversity Conservation in Thailand: A National Report; Office of Environment Policy and Planning, Ministry of Science Technology and Environment: Bangkok, Thailand, 2000.

10. MNRE. Thailand's Third National Communication (TNC) to the United Nations Framework Convention on Climate Change; Office of Natural Resources and Environmental Policy and Planning, Ministry of Natural Resources and Environment: Bangkok, Thailand, 2018.

11. DNP. Database of Nature Reserves in Thailand; National Parks Office, Department of National Parks, Wildlife and Plant Conservation: Bangkok, Thailand, 2017.

12. Wildlife Research Division. Status of Large Mammals in Thailand; Wildlife Conservation Office, Department of National Parks, Wildlife and Plant Conservation: Bangkok, Thailand, 2010.

13. Corlett, R.T. The Ecology of Tropical East. Asia, 3rd ed.; Oxford University Press: Oxford, UK, 2019.

14. Metzger, M.J.; Bunce, R.G.H.; Jongman, R.H.G.; Sayre, R.; Trabucco, A.; Zomer, R. A high-resolution bioclimate map of the world: A unifying framework for global biodiversity research and monitoring. Glob. Ecol. Biogeogr. 2013, 22, 630-638. [CrossRef]

15. Zomer, R.J.; Xu, J.; Wang, M.; Trabucco, A.; Li, Z. Projected impact of climate change on the effectiveness of the existing protected area network for biodiversity conservation within Yunnan Province, China. Biol. Conserv. 2015, 184, 335-345. [CrossRef]

16. Zomer, R.J.; Trabucco, A.; Metzger, M.J.; Wang, M.; Oil, K.P.; Xu, J. Projected climate change impacts on spatial distribution of bioclimatic zones and ecoregions within the Kailash Sacred Landscape of China, India, Nepal. Clim. Chang. 2014, 125, 445-460. [CrossRef]

17. Nwe, T.; Zomer, R.J.; Corlett, R.T. Projected impacts of climate change on the protected areas of Myanmar. Climate 2020, 8, 99. [CrossRef]

18. Hijmans, R.J.; Cameron, S.E.; Parra, J.L.; Jones, P.G.; Jarvis, A. Very high resolution interpolated climate surfaces for global land areas. Int. J. Climatol. 2005, 25, 1965-1978. [CrossRef]

19. Ramirez-Villegas, J.; Jarvis, A. Downscaling Global Circulation Model Outputs: The Delta Method Decision and Policy Analysis; International Center for Tropical Agriculture, CIAT: Cali, Colombia, 2010.

20. Hughes, A.C. Mapping priorities for conservation in Southeast Asia. Biol. Conserv. 2017, 209, 395-405. [CrossRef]

21. Van Vuuren, D.P.; Edmonds, J.; Kainuma, M.; Riahi, K.; Thomson, A.; Hibbard, K.; Hurtt, G.C.; Kram, T.; Krey, V.; Lamarque, J.F.; et al. The representative concentration pathways: An overview. Clim. Chang. 2011, 109, 5-31. [CrossRef]

22. Pumijumnong, N.; Bräuning, A.; Sano, M.; Nakatsuka, T.; Muangsong, C.; Buajan, S. A 338-year tree-ring oxygen isotope record from Thai teak captures the variations in the Asian summer monsoon system. Sci. Rep. 2020, 10, 8966. [CrossRef]

23. Bunyavejchewin, S.; Baker, P.J.; Davies, S.J. Seasonally dry tropical forests in continental Southeast Asia; structure, composition and dynamics. In The Ecology and Conservation of Seasonally Dry Forests in Asia; Smithsonian Institution Scholarly Press: Washington, DC, USA, 2011; pp. 9-35.

24. Hamilton, R.; Penny, D.; Hall, T.L. Forest, fire \& monsoon: Investigating the long-term threshold dynamics of south-east Asia's seasonally dry tropical forests. Quat. Sci. Rev. 2020, 238, 106334.

25. Kumar, D.; Pfeiffer, M.; Gaillard, C.; Langan, L.; Scheiter, S. Climate change and elevated CO2 favor forest over savanna under different future scenarios in South Asia. Biogeosci. Discuss. 2020. [CrossRef] 
26. Stevens, N.; Erasmus, B.F.; Archibald, S.; Bond, W.J. Woody encroachment over 70 years in South African savannahs: Overgrazing, global change, or extinction aftershock? Philos. Trans. R. Soc. Lond. B Biol. Sci. 2016, 371, 20150437. [CrossRef]

27. Thang, T.M.; Thu, A.M.; Chen, J. Tree species of tropical and temperate lineages in a tropical Asian montane forest show different range dynamics in response to climate change. Glob. Ecol. Conserv. 2020, 22, e00973. [CrossRef]

28. Suksawang, S. Protected area complexes: A new approach to connectivity in Thailand. Thai Forest Bull. Bot. 2018, 46, 25-33. [CrossRef]

29. Sukmasuang, R.; Charaspet, K.; Panganta, T.; Pla-ard, M.; Khioesree, N.; Thongbanthum, J. Diversity, abundance, activity period, and factors affecting the appearance of wildlife around the corridors between Khao Yai-Thap Lan National Parks, Thailand by camera trapping. Biodiversitas 2020, 21, 2310-2321. [CrossRef]

30. Corlett, R.T.; Westcott, D.A. Will plant movements keep up with climate change? Trends Ecol. Evol. 2013, 28, 482-488. [CrossRef]

31. Brito-Morales, I.; García Molinos, J.; Schoeman, D.S.; Burrows, M.T.; Poloczanska, E.S.; Brown, C.J.; Ferrier, S.; Harwood, T.D.; Klein, C.J.; McDonald-Madden, E.; et al. Climate velocity can inform conservation in a warming world. Trends Ecol. Evol. 2018, 33, 441-457. [CrossRef] [PubMed] 